\title{
Urinary incontinence related to perineal muscle strength in the first trimester of pregnancy: cross-sectional study
}

\author{
INCONTINÊNCIA URINÁRIA RELACIONADA À FORÇA MUSCULAR PERINEAL NO \\ PRIMEIRO TRIMESTRE DA GESTAÇÃO: ESTUDO TRANSVERSAL
}

\author{
INCONTINENCIA URINARIA RELACIONADA CON LA FUERZA MUSCULAR PERINEAL \\ EN EL PRIMER TRIMESTRE DEL EMBARAZO: ESTUDIO TRANSVERSAL
}

\author{
Maria Luiza Gonzalez Riesco ${ }^{1}$, Karina Fernandes-Trevisan ${ }^{2}$, Nathalie Leister ${ }^{3}$, Camila da Silva \\ $\mathrm{Cruz}^{4}$, Adriana de Souza Caroci ${ }^{5}$, Miriam Raquel Diniz Zanetti ${ }^{6}$
}

\begin{abstract}
Objective: To analyze pelvic floor muscle strength (PFMS), urinary continence and quality of life related to urinary incontinence (UI) of women in the first trimester of pregnancy. Method: Cross-sectional study with a sample of 500 women who started prenatal care in a complementary healthcare facility in Guarulhos, state of São Paulo, from 2012 and 2013. Pelvic floor muscle strength was evaluated through perineometry. The pregnant women who presented UI answered the International Consultation on Incontinence Questionnaire-Short Form (ICIQ-SF). Results: It was found that maternal age (OR=1.06; $\mathrm{Cl} 95 \%$ 1.02-1.11) and prior $\mathrm{UI}(\mathrm{OR}=15.12 ; 95 \% \mathrm{Cl}$ 8.19-27.92) are the variables that, in tandem, best explain the occurrence of $U I$ at the beginning of pregnancy. The mean score on the ICIQ-SF was $8.2(S D=3.9)$, considered a moderate impact on quality of life. Conclusion: Older pregnant women with prior UI are more likely to have UI in the first trimester of pregnancy.
\end{abstract}

\section{DESCRIPTORS}

Pregnancy

Muscle strength

Perineum

Urinary incontinence

Midwifery

\section{RESUMO}

Objetivo: Analisar a força dos músculos do assoalho pélvico (FMAP), a continência urinária e a qualidade de vida associada à incontinência urinária (IU) em mulheres no primeiro trimestre da gestação. Método: Estudo transversal cuja amostra incluiu 500 gestantes que iniciaram o pré-natal em um serviço do setor de saúde suplementar, em Guarulhos, SP, em 2012-2013. A FMAP foi avaliada por meio da perineometria e as gestantes com IU responderam - International Consultation on Incontinence Questionnaire-Short Form (ICIQ-SF). Resultados: A idade materna (OR=1,06 IC95\% 1,02-1,11) e IU prévia (OR=15,12; IC95\% 8,19-27,92) são as variáveis que, em conjunto, melhor explicam a ocorrência de IU no início da gestação. A média do escore do ICQ-SF foi 8,2 (d.p.=3,9), considerado como de impacto moderado na qualidade de vida. Conclusão: As gestantes com mais idade e com IU prévia têm maior chance de apresentar IU no primeiro trimestre da gravidez.

DESCRITORES
Gravidez
Força muscular
Períneo
Incontinência urinária
Enfermagem obstétrica

\section{RESUMEN}

Objetivo: Analizar la fuerza de los músculos del suelo pélvico (FMSP), la continencia urinaria y la calidad de vida en mujeres en el primer trimestre del embarazo. Método: Estudio transversal cuyo muestra incluyó 500 mujeres que comenzaron la atención prenatal en un servicio del sector de salud complementaria en Guarulhos, SP, en 2012-2013. La FMSP fue evaluada por la perineometría y las mujeres embarazadas con incontinencia urinaria (IU) respondieron al International Consultation on Incontinence Questionnaire-Short Form (ICIQ-SF). Resultados: Muestran que edad materna (OR=1,06 IC95\% 1,02-1,11) y IU previa $(\mathrm{OR}=15,12$; IC95\% 8,19-27,92) son las variables que, en conjunto, mejor explican la ocurrencia de IU al inicio del embarazo. La media del escore ICIQ-SF fue 8,2 (d.p.=3,9), considerado como de impacto moderado en la calidad de vida. Conclusión: Las embarazadas con más edad y con IU previa tienen chance mayor de presentar IU en el primer trimestre del embarazo.

DESCRIPTORES
Embarazo
Fuerza muscular
Perineo
Incontinencia urinaria
Enfermería obstétrica

\footnotetext{
Associate Professor, Department of Maternal-Child and Psychiatric Nursing, School of Nursing, University of São Paulo, São Paulo, São Paulo, Brazil. 2 Doctoral Student of the Nursing Graduate Program, School of Nursing, University of São Paulo, São Paulo, São Paulo, Brazil. ${ }^{3}$ Doctoral Student of the Nursing Graduate Program, School of Nursing, University of São Paulo, São Paulo, São Paulo, Brazil. ${ }^{4}$ Master's Student of the Nursing Graduate Program, School of Nursing, University of São Paulo, São Paulo, São Paulo, Brazil. ${ }^{5}$ Ph.D. Professor, Undergraduate Program in Midwifery, School of Arts, Sciences and Human Sciences, University of São Paulo, São Paulo, São Paulo, Brazil. ${ }^{6}$ Ph.D. Professor, Undergraduate Program in Physiotherapy, FIEO-UNIFIEO University Center, São Paulo, São Paulo, Brazil.
} 


\section{INTRODUCTION}

Urinary incontinence (UI) is a symptom of the lower urinary tract defined as involuntary loss of any quantity of urine $^{(1)}$. It impacts sexual, psychological and social health in women, affecting their quality of life $\mathrm{e}^{(2-3)}$.

Urinary incontinence during pregnancy and after birth has been widely studied, because during pregnancy at least $50 \%$ of women report loss of urine ${ }^{(4)}$, with many studies showing a high variation in quantities ${ }^{(5)}$.

Nerve and muscle trauma of the pelvic floor (PF) related to pregnancy and birth and weakness of the PF muscles are important predisposing factors for $\mathrm{UI}^{(6)}$.

Studies show that pregnancy, more than birth, is associated with triggering $\mathrm{UI}$, especially stress $\mathrm{UI}$, which is defined as involuntary loss of urine caused by effort, exercise, sneezing or coughing ${ }^{(1)}$. During pregnancy, its incidence gradually increases, progressively decreasing over the first 12 months after birth ${ }^{(4)}$.

A literature review, which included 22 cohort studies, showed that at least five etiological factors may be taken into consideration to explain the occurrence of stress UI: genetic factors, obesity, age, pregnancy and vaginal birth ${ }^{(7)}$.

A multicentric transversal study conducted in the southern and southeastern areas of Brazil with 495 women after birth showed that $71 \%$ had UI in the last four weeks of pregnancy. Factors associated to UI were: four or more children (OR=4.93; Cl95\% 2.15-11.32), obesity (OR=4.22; Cl95\% 2.098.54), low education (OR=2.99; CI95\% 1.74-5.12), previous vaginal birth (OR=2.59; $\mathrm{Cl} 95 \%$ 1.58-4.24) and black ethnicity $(\mathrm{OR}=2.32 ; \mathrm{Cl} 95 \% \text { 1.30-4.13) })^{(2)}$.

A prospective cohort study conducted with 618 primiparous Iranian women showed that UI before pregnancy, with at least one weekly occurrence, increased the risk for UI during pregnancy $(R R=5.75)$ and prolonged the duration of $\mathrm{UI}$ for one year $(R R=16.8)$, independently of the type of birth ${ }^{(8)}$.

There is strong evidence in literature to support preventive actions for UI during pregnancy, in particular maintaining adequate nutritional status and performing perineal exercises to strengthen the PF muscles ${ }^{(5,9)}$.

In relation to pelvic floor muscle strength (PFMS), the most common methods of evaluation in pregnant women are perineometry and digital vaginal palpation. Studies that use these instruments show conflicting results in regard to the preservation or decrease of PFMS during pregnancy and after birth ${ }^{(10-12)}$; however, decrease in PFMS has been pointed out as a predictor of $\mathrm{UI}^{(13-14)}$.

A transversal study conducted in Belo Horizonte, in the state of Minas Gerais, with 192 primiparous women between five and seven months after birth found PFMS $\leq 35.5 \mathrm{cmH} 2 \mathrm{O}$ as the stronger predictor of postpartum UI. Through multivariate analysis using the CART (classification and regression tree) model, the combination of PFMS $\leq 35.5$ with previous UI, newborn weight $>2,988$ grams and UI during pregnancy composed a predictive model for postpartum $\mathrm{UI}^{(15)}$.

Given the impact that UI has on quality of life, the International Consultation on Incontinence Questionnaire-Short Form (ICIQ-SF) has been used to measure this relationship. The ICIQ-SF was translated and revalidated for Portuguese ${ }^{(16)}$ and consisted of four questions related to frequency and quantity of urinary loss, the interference of such loss in daily life and situations when UI can occur.

There are many studies concerning UI and PFMS during pregnancy, but there is little data concerning this relationship in the first trimester. Therefore, the objective of this study was to analyze PFMS, urinary continence and quality of life related to UI of women in the first trimester of pregnancy.

\section{METHOD}

A transversal study concerning PFMS and UI of women in the first trimester of pregnancy conducted in the Prenatal and Obstetrics Clinical Center (Centro Clínico de Obstetrícia e Pré-Natal) of SEISA Medical Care (SEISA Assistência Médica), a complementary healthcare facility located in the city of Guarulhos, state of São Paulo.

The population was composed of women who started prenatal care in the center. All of the pregnant women who received care between November 2012 and September 2013 and who met the following inclusion criteria were included in the sample: age $\geq 18$ years; $\mathrm{BMI}<35$; completion of primary school; pregnancy only; gestational age $<13$ weeks; no previous urogenital surgery or disease that may affect PFMS; no resistance to insertion of the perineometer probe into the vagina; not perform the Valsalva maneuver for PFMS measurement; no difficulty understanding or communicating in the Portuguese language. The final sample totaled 500 pregnant women.

The dependent variable in the study was $U I$ in the prior four weeks and the independent variables were: maternal age (years); ethnicity (self-reported); educational level (complete primary or incomplete high school, complete high school or incomplete undergraduate, complete undergraduate); occupation (paid work, house work, student); marital status (lives with partner, does not have or does not live with partner); physical exercises before pregnancy (minimum frequency of two times per week); number of previous pregnancies, births and vaginal births; perineal trauma in previous birth (episiotomy or spontaneous laceration); high-weight newborn (in grams, immediately after birth); UI prior to current pregnancy; gestational age (weeks); nutritional status (low weight, adequate, overweight and obese, classified by body mass index, considering gestational age) ${ }^{(17)}$; PFMS (cmH2O); ICQ-SF score.

Data gathering was conducted immediately after the first prenatal consultation by the center's nurse-midwife or midwife. An interview was carried out using a form wi- 
th sociodemographic information, clinical and obstetrics history and the status of the current pregnancy.

To evaluate PFMS, a Peritron ${ }^{\mathrm{TM}}$ electronic pressure perineometer (LABORIE, Toronto, Canada) was used. It registers muscle contractions of the $\mathrm{PF}$ in $\mathrm{CmH} 2 \mathrm{O}$ through a sensor located in a silicon vaginal probe with a length of $8 \mathrm{~cm}$ and $a$ diameter of $3 \mathrm{~cm}$. The sensor is connected to a portable microprocessor that measures PFMS from 0.1 to $300 \mathrm{~cm} \mathrm{H} 2 \mathrm{O}$.

For this measurement, the pregnant women were in the gynecological position and were instructed to contract the PF musculature. The probe was covered with a disposable condom, externally lubricated with water-based gel and introduced between $4 \mathrm{~cm}$ and $6 \mathrm{~cm}$ into the vagina. The perineometer was calibrated by the probe being inserted into the vagina and inflated to $100 \mathrm{~cm} \mathrm{H2O}$; after that, the scale was reset to zero, following the manufacturer's recommendations. The women were asked to contract the PF musculature as hard as they could, sustaining the contraction for 5 seconds. This contraction was repeated three times with an interval of 30 seconds between one. Three PFMS values were registered, but only the highest was considered for analysis.

The women who reported UI during the last four weeks in the interview answered the self-applied ICIQ-SF questionnaire. Values are attributed for questions related to frequency and quantity of urine loss and the interference of such loss in daily life, with a final score that varies from 0 to 21.

Data were entered into Microsoft Excel ${ }^{\mathrm{TM}}$ and analyzed using the statistical software Minitab ${ }^{\mathrm{TM}}$, version 16.1, and SPSS $^{\text {TM }}$, version 17.0.

In univariate analysis, the comparison among pregnant women with and without UI was conducted with a chi-square test (for the categorical variables), a t-test for independent samples (for the quantitative variables with normal distribution) and a Mann-Whitney test (when assumption of normality was not considered). All tests were conducted using the two-tailed method, with a significance level of $5 \%(p \leq 0.05)$.

In multivariate analysis, a logistic regression model was used to determine factors associated with UI, with all variables that presented a statistical significance of at least $20 \%(p \leq 0.20)$ in univariate analysis. The final model was obtained through the backward process, in which less sig- nificant variables were removed from the model, one by one, until only those with a $5 \%$ significance level remained.

A receiver operating characteristic (ROC) curve was constructed for the quantitative variables that presented statistical significance in univariate analysis (except the number of prior pregnancies, prior births and prior vaginal births) with the objective of verifying the best cut-off point to discriminate pregnant women with or without UI. The relation between PFMS and the ICIQ-SF score was analyzed with a Spearman's correlation.

The study was approved by the Research Ethics Committee of the School of Nursing of the University of São Paulo (CAAE: 05096412.7.0000.5392). The women's participation was voluntary, through reading and signing a Free and Informed Consent form.

\section{RESULTS}

Of a total of 1,266 women who began the prenatal care process at the center during the study period, 766 were not included because they did not meet the established criteria ( $n=648$ ) or because they refused to participate $(n=118)$. Therefore, the final total was 500 pregnant women.

The average gestational age was 8.5 weeks (SD =1.9), 95 (19\%) pregnant women presented UI, of whom 37 (38.9\%) were primigravidas. The UI percentage among primigravidas was $7.4 \%$ and among women with one or more prior pregnancies, $11.6 \%$. The average PFMS was 30.5 (SD =17.3), with $27.2(S D=15.8) \mathrm{cmH} 2 \mathrm{O}$ and $31.1(\mathrm{SD}=17.6) \mathrm{cmH} 20$, among pregnant women with and without $\mathrm{UI}$, respectively.

Tables 1 and 2 show the quantitative and categorical variables of the characteristics of pregnant women with or without UI.

Urinary incontinence was more frequent among pregnant women of higher age, with more prior pregnancies, births and vaginal births, with perineal trauma from prior births, overweight and obesity, previous $\mathrm{UI}$ and PFMS $<30$ $\mathrm{cmH} 2 \mathrm{O}$, with statistically significant differences.

The variables ethnicity, occupation and marital status, although not significant at the $5 \%$ level, were relatively close to statistical significance. All remaining variables did not reach statistical significance.

Table 1 - Quantitative variables of the characteristics of pregnant women with and without UI — Guarulhos, state of São Paulo, 2012-2013

\begin{tabular}{llll}
\hline Variable & With UI & Without UI & p-value \\
\hline Maternal age (years) & $29.4(6.3)$ & $25.5(5.9)$ & $0.007^{*}$ \\
Average (SD) & 30 & 27 & \\
Median & $18-46$ & $18-45$ & \\
Min - max & & $0.7(0.9)$ & $0.006 \dagger$ \\
Previous pregnancies & $1.0(1.2)$ & 0 & \\
Average (SD) & 1 & $0-7$ & \\
Median & $0-5$ & & \\
Min- $\max$ & & & \\
\hline
\end{tabular}




\begin{tabular}{|c|c|c|c|}
\hline \multicolumn{4}{|l|}{ Continuation... } \\
\hline Variable & With UI & Without UI & p-value \\
\hline \multicolumn{4}{|c|}{ Previous births } \\
\hline Average (SD) & $0.9(1.0)$ & $0.5(0.7)$ & $<0.001 *$ \\
\hline Median & 1 & 0 & \\
\hline $\operatorname{Min}-\max$ & $0-4$ & $0-5$ & \\
\hline \multicolumn{4}{|c|}{ Previous vaginal births } \\
\hline Average (SD) & $0.6(0.9)$ & $0.3(0.6)$ & $<0.001 *$ \\
\hline Median & 0 & 0 & \\
\hline $\operatorname{Min}-\max$ & $0-4$ & $0-4$ & \\
\hline \multicolumn{4}{|c|}{ Newborn with highest weight (g) } \\
\hline Average (SD) & $3,145(656)$ & $3,128(578)$ & $0.867 \dagger$ \\
\hline Median & 3200 & 3200 & \\
\hline Min $-\max$ & $1,100-4,900$ & $500-5,370$ & \\
\hline
\end{tabular}

${ }^{*}$ Whitney-Mann test; $\nmid t$-test for independent samples

Table 2 - Categorical variables of the characteristics of pregnant women with and without UI — Guarulhos, state of São Paulo, 2012-2013

\begin{tabular}{|c|c|c|c|}
\hline \multirow[t]{2}{*}{ Variable } & \multirow{2}{*}{$\begin{array}{c}\text { With UI } \\
\text { n (\%) }\end{array}$} & \multirow{2}{*}{$\begin{array}{c}\text { Without UI } \\
\text { n (\%) }\end{array}$} & \multirow[t]{2}{*}{ p-value* } \\
\hline & & & \\
\hline \multicolumn{4}{|l|}{ Ethnicity } \\
\hline Mixed, black, yellow & $65(68.4)$ & $248(61.4)$ & 0.202 \\
\hline White & $30(31.6)$ & $156(38.6)$ & \\
\hline \multicolumn{4}{|l|}{ Education level } \\
\hline Complete primary or incomplete high school & $12(12.6)$ & $41(10.2)$ & 0.764 \\
\hline Complete high school or incomplete undergraduate & $66(69.5)$ & $285(70.5)$ & \\
\hline Complete graduate & $17(17.9)$ & $78(19.3)$ & \\
\hline \multicolumn{4}{|l|}{ Occupation } \\
\hline Paid work & $79(83.2)$ & $310(76.5)$ & 0.163 \\
\hline House worker or student & $16(16.8)$ & $95(23.5)$ & \\
\hline \multicolumn{4}{|l|}{ Marital status } \\
\hline Lives with partner & $87(92.5)$ & $344(85.4)$ & 0.064 \\
\hline Does not have or does not live with partner & $7(7.5)$ & $59(14.6)$ & \\
\hline \multicolumn{4}{|l|}{ Physical exercise } \\
\hline Yes & $20(21.1)$ & $107(26.5)$ & 0.269 \\
\hline No & $75(78.9)$ & $296(73.5)$ & \\
\hline \multicolumn{4}{|l|}{ Perineal trauma from previous birth } \\
\hline Yes & $35(36.8)$ & $84(20.8)$ & 0.001 \\
\hline No & $60(63.2)$ & $320(79.2)$ & \\
\hline \multicolumn{4}{|l|}{ Gestational age (weeks) } \\
\hline 4 to 8 & $44(46.3)$ & $213(52.6)$ & 0.271 \\
\hline 9 to 12 & $51(53.7)$ & $192(47.4)$ & \\
\hline \multicolumn{4}{|l|}{ Nutritional state } \\
\hline Low weight & $3(3.2)$ & $43(10.7)$ & 0.018 \\
\hline Adequate & $39(41.1)$ & $187(46.6)$ & \\
\hline Overweight & $35(36.8)$ & $128(31.9)$ & \\
\hline Obese & $18(18.9)$ & $43(10.7)$ & \\
\hline \multicolumn{4}{|l|}{ Previous UI } \\
\hline Yes & $81(85.3)$ & $114(28.2)$ & $<0.001$ \\
\hline No & $14(14.7)$ & $290(71.8)$ & \\
\hline \multicolumn{4}{|l|}{ PFMS (cmH2O) } \\
\hline$<30$ & $62(65.3)$ & $215(53.1)$ & 0.032 \\
\hline$\geq 30$ & $33(34.7)$ & $190(46.9)$ & \\
\hline
\end{tabular}

${ }^{{ }^{*}}$ Chi-square test. 
During multivariate analysis of factors associated with UI, the following variables, which presented a $p$-value $\leq 20$, were included in the logistic regression model: maternal age, previous vaginal births, ethnicity, occupation, marital status, nutritional state, prior UI and PFMS (Table 3).

The variables number of previous pregnancies, number of previous births and perineal trauma had a very high significance in univariate analysis $(p=0.006, p<0.001$ and $p=0.001$, respectively), but were not included in the multivariate model, because they are highly correlated among themselves and with the variable previous vaginal births.

Table 3 - Initial model of logistic regression of variables associated with UI in the first trimester of pregnancy - Guarulhos, State of São Paulo, 2012 - 2013

\begin{tabular}{|c|c|c|c|}
\hline Variable & OR & CI95\% & p-value \\
\hline Maternal age & 1.04 & $0.99-1.09$ & 0.118 \\
\hline Previous vaginal births & 1.44 & $0.98-2.11$ & 0.060 \\
\hline \multicolumn{4}{|l|}{ Ethnicity } \\
\hline White & 1 & & \\
\hline Mixed/black/yellow & 1.37 & $0.77-2.42$ & 0.280 \\
\hline \multicolumn{4}{|l|}{ Occupation } \\
\hline House worker or student & 1 & & \\
\hline Paid work & 1.81 & $0.91-3.60$ & 0.090 \\
\hline \multicolumn{4}{|l|}{ Marital status } \\
\hline $\begin{array}{l}\text { Does not have or does not live with } \\
\text { partner }\end{array}$ & 1 & & \\
\hline Lives with partner & 2.04 & $0.78-5.30$ & 0.144 \\
\hline \multicolumn{4}{|l|}{ Nutritional state } \\
\hline Adequate & 1 & & \\
\hline Low weight & 0.30 & $0.08-1.13$ & 0.075 \\
\hline Overweight & 1.17 & $0.64-2.14$ & 0.611 \\
\hline Obese & 1.44 & $0.66-3.11$ & 0.359 \\
\hline \multicolumn{4}{|l|}{ Previous UI } \\
\hline No & 1 & & \\
\hline Yes & 15.14 & $8.08-28.39$ & $<0.001$ \\
\hline \multicolumn{4}{|l|}{ PFMS (cmH2O) } \\
\hline$\geq 30$ & 1 & & \\
\hline$<30$ & 1.50 & $0.87-2.58$ & 0.150 \\
\hline
\end{tabular}

Table 4 presents a final model of the multivariate analysis, indicating that the variables that, in tandem, best explain the occurrence of $\mathrm{UI}$ are maternal age (chance of UI increases 1.06 times as the pregnant women age) and previous UI (pregnant females who had had UI have a 15.12 times higher chance of presenting UI in the current pregnancy). The variable number of previous vaginal births presented a significance level very close to $5 \%$ and, if kept in the model, the results do not change significantly maternal age: OR $=1.05 ; \mathrm{CI} 95 \% 1.00$ - 1.09; $p=0.033$; previous UI: OR = 14.58; CI95\% 7.87 - 26.98; $p<0,001$; previous vaginal births: $O R=1.43$; $\mathrm{Cl} 95 \%=1.00-2.06 ; \mathrm{p}=0.052)$.
Table 4 - Final model of logistic regression of variables associated with UI in the first trimester of pregnancy — Guarulhos, State of São Paulo, 2012 - 2013

\begin{tabular}{llll}
\hline Variable & OR & IC 95\% & p-value \\
\hline Maternal age & 1.06 & $1.02-1.11$ & 0.006 \\
Previous UI & & & \\
No & 1 & & \\
Yes & 15.12 & $8.19-27.92$ & $<0.001$ \\
\hline
\end{tabular}

PFMS evaluation through a receiver operating characteristic (ROC) curve was significant for the effect of UI $(p=0.045)$, with an area under the curve of 0.556 . The best cut-off point was $28.5 \mathrm{cmH} 2 \mathrm{O}$, with a sensitivity of $64.2 \%$ and specificity of $49.4 \%$.

In the multivariate model, to obtain factors associated with UI, PFMS was dichotomized in $<30$ and $\geq 30 \mathrm{cmH} 2 \mathrm{O}$. However, according to the results of the analysis through the ROC curve, the best cut-off point to evaluate UI is 28.5 $\mathrm{cmH} 2 \mathrm{O}$. Therefore, the multivariate model was reconstructed with the same parameters shown in Table 3 , but using a new dichotomization for PFMS $(<28.5$ and $\geq 28.5$ $\mathrm{cmH} 2 \mathrm{O}$ ). Even with that, PFMS was still not significant, resulting in a final model similar to the one from Table 4.

Of the 95 pregnant women with UI, 90 were evaluated through the ICIQ-SF questionnaire. The scores obtained varied from 2 to 18 points, with an average of 8.2 points (SD = 3.9) and a median of 8 points. For the same pregnant women, PFMS varied from 1.6 to $69.1 \mathrm{cmH} 2 \mathrm{O}$, with an average of 27.7 $(S D=15.7 \%)$ and a median of 25.9. The correlation between ICIQ-SF and PFMS was -0.115 , not significant $(p=0.279)$.

\section{DISCUSSION}

Data from this study are part of the first stage of an ongoing cohort study with women during pregnancy and postpartum. Follow-up with these women is performed in the second and third trimesters of pregnancy and at 45 , 90 and 180 days after birth.

The occurrence of UI in $19 \%$ of the pregnant women in this study is among the lowest reported in the literature, since reviews regarding UI epidemiology in pregnancy show percentages of up to $75 \%{ }^{(4-5)}$. It should be noted that most of the data in these reviews comes from studies with women after the second trimester of pregnancy.

A cohort study with 1,128 nulliparous pregnant women without previous $\mathrm{UI}$ in the first trimester of pregnancy identified a prevalence of $8.3 \%$ of UI (CI95\% $6.6-10.0)^{(18)}$, close to the percentage of $7.4 \%$ among the primigravidas in this study.

According to multivariate analysis, higher maternal age (OR = 1.06; CI95\% $1.02-1.11$ ) and previous UI (OR = 1.06; CI95\% 1.02 - 1.11) explain, in tandem, the occurrence of $\mathrm{UI}$ in the first trimester of pregnancy. This result is compatible with other studies that show that these same variables may be predictors of UI during pregnancy. 
Maternal age was related to $\mathrm{UI}$ in a cross-sectional study ${ }^{(19)}$ and in two literature reviews ${ }^{(9,20)}$. In the crosssectional study ${ }^{(19)}$, the chances of UI increased according to age $(O R=1.05 \mathrm{Cl} 95 \% 1.01-1.09)$. In one of the reviews, a cut-off point of 35 years of age was shown in the referenced studies as a risk factor for $\mathrm{UI}^{(20)}$. In the other review, age was an independent factor for $\mathrm{UI}$ in more than 20 studies, with an evidence level of 2 (based on low quality random clinical trials and good quality cohort studies) ${ }^{(9)}$.

Regarding history of $\mathrm{UI}$, a cohort study with 618 pregnant Iranian women with light stress UI during pregnancy (up to one episode of urine loss per week) showed a relative UI risk of 5.75 among those with previous $\mathrm{UI}^{(8)}$. A crosssectional study with 300 women in the second trimester of pregnancy showed that, among $46(15.3 \%)$ pregnant women who had UI, 95.7\% had previous UI history ${ }^{(21)}$.

Regarding the remaining factors mentioned in the literature as associated with UI (ethnicity, education level, occupation, marital status, physical exercises, previous pregnancies and births, newborn weight, nutritional status, PFMS $)^{(2,5,7,9,13-14,22-23)}$, only a few had statistical significance in the univariate analysis. An explanation for the fact that in the multivariate analysis previous births, PFMS and nutritional status were not associated with UI among the pregnant women in this study may be related to low parity, early gestational age and the fact that only pregnant women with a $\mathrm{BMI}<35$ were included in the study.

There are no data in the literature regarding the relationship between PFMS and UI in the first trimester of pregnancy. However, studies that evaluated PFMS using the Peritron ${ }^{\mathrm{TM}}$ in women with UI between 20 and 34 weeks of pregnancy ${ }^{(13)}$ and in the postpartum period ${ }^{(15)}$ found the averages $\leq 30.05 \mathrm{cmH} 2 \mathrm{O}(\mathrm{SD}=11.05)$ and $=19.3$ $(S D=13.1) \mathrm{cmH} 2 \mathrm{O}$, respectively.

The results of the present study of women in the first trimester of pregnancy are close to the results obtained among those starting from the second half of pregnancy ${ }^{(13,21,24)}$, considering that the proportion of pregnant women with PFMS $<30 \mathrm{cmH} 2 \mathrm{O}$ was higher among those with UI (average $=27.2, \mathrm{SD}=15.8$ ), in comparison to continent women (average $=31.3 ; \mathrm{SD}=17.6$ ).

\section{REFERENCES}

1. Abrams P, Cardozo L, Fall M, Griffiths D, Rosier P, Ulmsten U, et al. The standardisation of terminology in lower urinary tract function: report from the Standardisation Sub-Committee of the International Continence Society. Urology. 2003;61(1):37-49.

2. Oliveira C, Seleme M, Cansi PF, Consentino RF, Kumakura FY, Moreira GA, et al. Urinary incontinence in pregnant women and its relation with socio-demographic variables and quality of life. Rev Assoc Med Bras. 2013;59(5):460-6.
Even though the PFMS cut-off point of $30 \mathrm{cmH} 2 \mathrm{O}$ established for analysis was higher than that obtained from the ROC curve, this value agreed with what was found in the literature ${ }^{(13,15)}$ and may serve as parameter for new studies and clinical practice.

It is worth considering that, although the best cut-off point was $28.5 \mathrm{cmH} 2 \mathrm{O}$ according to the ROC curve, its sensitivity and specificity are insufficient to define this value.

Therefore, although it is not kept as predictor of $\mathrm{UI}$ in the final analysis model, pregnant women can be oriented to perform exercises to strengthen the $\mathrm{PF}$, with or without biofeedback, to reach PFMS values higher than $30 \mathrm{cmH} 2 \mathrm{O}$, as support for the prevention and treatment of $\mathrm{UI}^{(13,21,23)}$.

Regarding the impact of $\mathrm{UI}$ in the life of the women, even when loss is minimal it may cause social embarrassment and sexual dysfunction, significantly interfering in their physical and mental health ${ }^{(25-26)}$.

In this study, the average $(8.2 ; \mathrm{SD}=3.9)$ and the median (8) of the ICIQ-SF score showed values that were compatible with moderate impact on the quality of life of pregnant women with $\mathrm{UI}$, considering the classification into four categories of severity: light (1-5), moderate (6-12), heavy (13-18) and very heavy $(19-21)^{(28)}$.

A cross-sectional study with 298 incontinent women of various ethnicities and gestational ages between 26 and 30 weeks showed an ICIQ-SF score of $6.3(S D=3.5)$ ${ }^{(19)}$. Another prospective cohort study with 327 primiparous women had a score of 6.2 related to the last trimester of pregnancy ${ }^{(27)}$. These scores, although lower than in this study, are also compatible with moderate impact on quality of life. However, a cross-sectional study carried out in Brazil identified an ICIQ-SF score that was higher (12.11; $S D=4.04)$ among 352 women at the end of pregnancy ${ }^{(2)}$

\section{CONCLUSION}

Older pregnant women with previous UI history had a higher chance of presenting $\mathrm{UI}$ in the first trimester of pregnancy. PMFS $<28.5 \mathrm{cmH} 2 \mathrm{O}$ represented a cut-off point for $\mathrm{UI}$, in spite of limited sensitivity and specificity, and UI had moderate impact on the quality of life of these women
3. Torrisi G, Minini G, Bernasconi F, Perrone A, Trezza G, Guardabasso $\mathrm{V}$, et al. A prospective study of pelvic floor dysfunctions related to delivery. Eur J Obstet Gynecol Reprod Biol. 2012;160(1):110-5.

4. Wesnes SL, Hunskaar S, Rortveit G. Epidemiology of urinary incontinence in pregnancy and postpartum. In: Alhasso A, editor. Urinary incontinence [Internet]. Rijeka: InTech; 2012. p.21-40. [cited 2014 Mar 1]. Available from: http://www.intechopen. com/download/get/type/pdfs/id/34718 . 
5. Sangsawang B, Sangsawang N. Stress urinary incontinence in pregnant women: a review of prevalence, pathophysiology, and treatment. Int Urogynecol J. 2013;24(6):901-12.

6. Luthander C, Emilsson T, Ljunggren G, Hammarström M. A questionnaire on pelvic floor dysfunction postpartum. Int Urogynecol J. 2011;22(1):105-13.

7. Fritel $X$, Ringa $V$, Quiboeuf E, Fauconnier A. A. Female urinary incontinence, from pregnancy to menopause: a review of epidemiological and pathophysiological findings. Acta Obstet Gynecol Scand. 2012;91(8):901-10.

8. Hantoushzadeh $\mathrm{S}$, Javadian $\mathrm{P}$, Shariat M, Salmanian B, Ghazizadeh S, Aghssa M. Stress urinary incontinence: pre-pregnancy history and effects of mode of delivery on its postpartum persistency. Int Urogynecol J. 2011;22(6):651-5.

9. Wesnes SL, Lose G. Preventing urinary incontinence during pregnancy and postpartum: a review. Int Urogynecol J. 2013;24(6):889-99.

10. Caroci AS, Riesco MLG, Sousa WS, Cotrim AC, Sena EM, Rocha NL, et al. Analysis of pelvic floor musculature function during pregnancy and postpartum: a cohort study. J Clin Nurs. 2010;19(17-18):2424-33.

11. Elenskaia K, Thakar R, Sultan AH, Scheer I, Beggs A. The effect of pregnancy and childbirth on pelvic floor muscle function. Int Urogynecol J. 2011;22(11):1421-7.

12. Gameiro MO, Sousa VO, Gameiro LF, Muchailh RC, Padovani $\mathrm{CR}$, Amaro JL. Comparison of pelvic floor muscle strength evaluations in nulliparous and primiparous women: a prospective study. Clinics (São Paulo). 2011;66(8):1389-93.

13. Dinc A, Beji NK, Yalcin O. Effect of pelvic floor muscle exercises in the treatment of urinary incontinence during pregnancy and the postpartum period. Int Urogynecol J. 2009;20(10):1223-31.

14. Barbosa AMP, Dias A, Marini G, Calderon IM, Witkin S, Rudge MV. Urinary incontinence and vaginal squeeze pressure two years post-cesarean delivery in primiparous women with previous gestational diabetes mellitus. Clinics (São Paulo). 2011;66(8):1341-5.

15. Baracho SM, Silva LB, Baracho E, Silva Filho AL, Sampaio RF, Figueiredo EM. Pelvic floor muscle strength predicts stress urinary incontinence in primiparous women after vaginal delivery. Int Urogynecol J. 2012;23(7):899-906.

16. Tamanini JTN, Dambros M, D’Ancora CAL, Palma PC, Rodrigues Netto Jr. N. Validação para o português do "International Consultation on Incontinence Questionnaire-Short Form" (ICIQSF). Rev Saúde Pública. 2004;38(3):438-44.
17. Atalah ES, Castillo LC, Castro SR, Aldea P. Propuesta de un nuevo estandar de evaluación nutricional en embarazadas. Rev Med Chil. 1997;125(12):1429-36.

18. Solans-Domenech M, Sanchez E, Espuna-Pons M. Urinary and anal incontinence during pregnancy and postpartum: incidence, severity, and risk factors. Obstet Gynecol. 2010;115(3):618-28.

19. Bø K, Øglund GP, Sletner L, Mørkrid K, Jenum AK. The prevalence of urinary incontinence in pregnancy among a multi-ethnic population resident in Norway. BJOG. 2012;119(11):1354-60.

20. Cerruto MA, D’Elia C, Aloisi A, Fabrello M, Artibani W. Prevalence, incidence and obstetric factors impact on female urinary incontinence in Europe: a systematic review. Urol Int. 2013;90(1):1-9.

21. Hilde G, Stær-Jensen J, Ellström Engh M, Brækken IH, Bø K. Continence and pelvic floor status in nulliparous women at midterm pregnancy. Int Urogynecol J. 2012;23(9):1257-63.

22. Hantoushzadeh S, Javadian P, Shariat M, Salmanian B, Ghazizadeh S, Aghssa M. Stress urinary incontinence: pre-pregnancy history and effects of mode of delivery on its postpartum persistency. Int Urogynecol J. 2011;22(6):651-5.

23. Higa R, Lopes MHBM, Reis MJ. Risk factors for urinary incontinence in women. Rev Esc Enferm USP. 2008;42(1):187-92.

24. Hay-Smith J, Mørkved S, Fairbrother KA, Herbison GP. Pelvic floor muscle training for prevention and treatment of urinary and faecal incontinence in antenatal and postnatal women. Cochrane Database Syst Rev. 2008;(4):CD007471.

25. Leroy LS, Lopes MHBM. Urinary incontinence in the puerperium and its impact on the health-related quality of life. Rev Latino Am Enfermagem. 2012;20( 2):346-53.

26. Lopes DB, Praça NS. Self-reported urinary incontinence in the postpartum period: clinical characteristics. Rev Esc Enferm USP. 2012;46(3):559-64.

27. Klovning A, Avery K, Sandvik H, Hunskaar S. Comparison of two questionnaires for assessing the severity of urinary incontinence: the ICIQ-UI SF versus the Incontinence Severity Index. Neurourol Urodyn. 2009;28(5):411-5.

28. Hansen BB, Svare J, Viktrup L, Jørgensen T, Lose G. Urinary incontinence during pregnancy and 1 year after delivery in primiparous women compared with a control group of nulliparous women. Neurourol Urodyn. 2012;31(4):475-80.

\section{Acknowledgement}

For the São Paulo Research Foundation (Fundação de Amparo à Pesquisa do Estado de São Paulo) And the National Council for Scientific and Technological Development (Conselho Nacional de Desenvolvimento Científico e Tecnológico).

Correspondence addressed to: Maria Luiza Gonzalez Riesco Departamento de Enfermagem Materno-Infantil e Psiquiátrica, Escola de Enfermagem da USP

Av. Dr. Enéas de Carvalho Aguiar, 419 - Cerqueira César CEP 05403-000 - São Paulo, SP, Brazil

E-mail: riesco@usp.br 